\title{
Effects of SP6 Acupuncture Point Stimulation on Labor Pain and Duration of Labor
}

\author{
Kiymet Yesilcicek Calik ${ }^{1, *} ;$ Nuran Komurcu $^{2}$ \\ ${ }^{1}$ Department of Obstetrics and Gynecology Nursing, Faculty of Health Sciences, Karadeniz Technical University, Trabzon, Turkey \\ ${ }^{2}$ Department of Obstetrics and Gynecology Nursing, Faculty of Health Sciences, Marmara University, Istanbul, Turkey \\ ${ }^{*}$ Corresponding Author: Kiymet Yesilcicek Calik, Department of Obstetrics and Gynecology Nursing, Faculty of Health Sciences, Karadeniz Technical University, Trabzon, Turkey. Tel: \\ +90-4622300476, Fax:+90-4622300475, E-mail: omrumyesilcicek@hotmail.com; kyesilcicek@ktu.edu.tr
}

Received: November 28, 2013; Revised: April 26, 2014; Accepted: May 19, 2014

Background: Acupressure has been used frequently to improve labor, manage labor pain, and shorten delivery time. However, there has been little research-based evidence to support the positive effects of acupressure in the obstetric area and obstetric nursing.

Objectives: The aim of this study was to evaluate the effects of SP6 acupressure on labor pain and delivery time in primigravida women in labor.

Patients and Methods: The study was conducted at the Trabzon Maternity Hospital in Turkey. Its design was a randomized controlled clinical trial study using a single-blinded method. One hundred (100) primigravida women in labor were randomly assigned to either the SP6 acupressure $(n=50)$ or control group $(n=50)$. Acupressure was practiced 35 times in total on the SP6 point of both legs in the SP6 acupressure group; 15 times (during contraction) when cervical dilation was 2-3 cm, 10 times when cervical dilation was 5-6 cm and 10 times at 9-10 cm dilation, while the women in the control group received standard care. Labor pain was measured five times using a structured questionnaire of a subjective labor pain scale (visual analogue scale-VAS) when dilation was 2-3 cm (VAS2), 5-6 cm (VAS3) and 8-9 $\mathrm{cm}$ (VAS 4) before and after acupressure was applied to the SP6 point(VAS1), and finally at the early postpartum period (VAS5). The duration of labor in both groups was measured with a partograph and the length of delivery time was calculated in two stages: from $3 \mathrm{~cm}$ cervical dilation to full cervical dilation, and from full cervical dilation to delivery.

Results: There were significant differences between the groups in subjective labor pain scores (except VAS 4$)(\mathrm{P}<0.001)$. The duration of the Phase one ( $3 \mathrm{~cm}$ dilatation to full dilatation) and Phase two (full dilatation to birth) in the acupressure group was shorter than the control group (Phase one, $225 \mathrm{~min}$ and $320 \mathrm{~min}$, respectively; Phase two, $15 \mathrm{~min}$ and $20 \mathrm{~min}$, respectively; both P $<0.001$ ).

Conclusions: It was determined that SP6 acupressure was effective in decreasing pain and duration of labor.

Keywords:Acupressure; Acupuncture point; Labor; Labor Pain; Randomized Clinical Trial

\section{Background}

Labor pain is recognized as one of the most severe and acute human pain. However, modern obstetrical practice rejects the belief that labor pain is acceptable or even necessary (1). The American Society of Anesthesiologists and the American College of Obstetrics and Gynecology recognize labor pain as an indication for treatment $(1,2)$. Although labor pain is an important biological sign indicating that labor is starting, it should be terminated when its purpose has ended. Labor pain stimulates the sympathetic system by causing neuroendocrine stress response, increased levels of ACTH, cortisol, epinephrine, norepinephrine and $\beta$-endorphine. It also reduces blood flow to the uterus, causing acidosis and fetal hypoxia (1). For these reasons, labor pain should be absolutely eliminated. There are two ways to eliminate labor pain. The first is through more commonly used pharmacological methods, and the second is with non-pharmacological methods, which are used less frequently (3) Non-pharmacological methods, such as acupressure, offer sufficient pain control and are harmless for mother and fetus under proper medical supervision. Moreover, these methods do not slow down labor and have no side effects or allergy-related risks $(1,4)$. One of the non-pharmacological methods that are used to reduce labor pain and to shorten the duration of labor is acupressure (5-11). Acupressure is a means of manipulating the same acupoints as used in acupuncture, but without the use of needles $(5,12$, 13). Acupressure used on the BL60, BL67, GB21, LI4, SP9 and SP6 sites affects uterine contractions or duration of labor by stimulating the secretion of oxytocin from the hypophysis $(3,5,13,14)$. The SP6 point is the junction point of the liver, spleen, and kidney meridians. Based on principles of traditional Chinese medicine, this acupuncture point is used to strengthen the spleen restoring balance to the Yin and to the blood, liver and kidneys. This SP6 point is also commonly used in the treatment of reproductive conditions in women, such

Copyright ( ) 2014, Iranian Red Crescent Medical Journal; Published by Kowsar. This is an open-access article distributed under the terms of the Creative Commons Attribution-NonCommercial 4.0 International License (http://creativecommons.org/licenses/by-nc/4.0/) which permits copy and redistribute the material just in noncommercial usages, provided the original work is properly cited. 
Yesilcicek Calik K et al.

as labor induction and pain relief during labor (11, 1416). In addition, acupressure prevents the increase of levels of catecholamine, beta endorphins, ACTH and cortisol in the pregnant woman by reducing the neuroendocrine response to pain. Thus, maternal metabolic speed, oxygen consumption and risk of acidosis and cardiovascular side effects are prevented and the progress of labor is facilitated $(2,4,13,17)$. Yet, the precise mechanism by which acupressure lessens pain is not clear (18). More studies are needed to establish safe and effective pain-relieving strategies to increase the comfort levels of pregnant women during labor, one of the most difficult experiences in a woman's life.

\section{Objectives}

Therefore, the aim of this study was to evaluate the effects of SP6 acupressure on labor pain and delivery time in primigravida women in labor, aiming as well to improve the effective use of the SP6 point.

\section{Patients and Methods}

A single-blind randomized clinical trial was conducted at Trabzon Maternity Hospital in Trabzon, Turkey between August 2009 and April 2010 on primigravida women who had been admitted to the delivery ward. Trabzon Maternity Hospital is a public hospital with approximately 6188 deliveries (3170 vaginal delivery and cesarean 3018) per year. As the largest obstetrics hospital in the area with a bed capacity of 300, it was therefore chosen for this study. Power analysis was done to calculate sample size before starting work. Considering the findings in a similar study made by Kashanian and Shahali which demonstrated that 0.85 strength $(d=0.55)$ could be achieved when there were 60 participants in each group, this study was also planned to be carried out with 60 participants in each group (19). While the study was being conducted, there were leavers due to various reasons (Figure 1) and some participants excluded from the study, so ultimately the study was completed with 50 people in each group. There were 50 people in each group in the post-hoc power analysis (NQuery Advisor Statistical Power Analysis for Software) using the Man-Whitney U test. According to the variable VAS 2 during the latent phase at $\mathrm{P}<0.05$ significance level, and at 95\% confidence interval, the power of the test study was determined as 0.99 . This finding demonstrates sample adequacy $(17,20)$. After the participants were thoroughly instructed in the aims and details of the study, an information sheet was provided and their informed consent was obtained. Participants signed the consent form knowing that they could withdraw from the study at any time. Additional criteria for participation in the study required women who would give birth at full term for the first time (between the 37th and 41st week of pregnancy), had one fetus with a weight of 2500-4000 gr according to ultrasound, had no pregnancy complications, were able to communicate effectively both orally and in written form, were primary school graduates or more, had no systemic or neurological disorder, had an intact membrane, were in the latent phase of labor (cervical opening 2-cm), had no damage, bruises or irritation at the SP6 acupoint, and had similar obstetric histories and socio-demographic characteristics. Excluded from the study were women who took narcotics, analgesics or sedatives during labor, had any sign of fetal distress, had a previous hysterectomy or uterine scar had any medical or surgical complications of pregnancy, had a history of drug use outside of the usual supplements, exhibited high risk pregnancies, or had postnatal complications or cesarean delivery. Although 193 women initially agreed to participate, only $100 \mathrm{com}$ pleted the study. Ninety-three women were excluded from the study for the following reasons: 41 women gave birth by cesarean, 19 had a prolonged labor, nine developed fetal distress, seven were taken to the obstetric table without $10 \mathrm{~cm}$ dilation or wanted to withdraw from the study, 13 women developed complications, and four were administered narcotic analgesics. When the women who had agreed to participate in the study experienced regular uterine contractions, they were taken to the labor and delivery room. After examining them for parity, cervical dilation status, and status of the intact membrane the participants were randomly assigned to either the experimental $(n=50)$ or the control group $(n=50)$. Pregnant women were assessed in terms of study inclusion criteria and randomization was made after determining their acceptance. The women were randomly divided into two groups (two parts, block random using sealed, sequentially) distributed envelopes to which the letters A and C had been allocated. The letter A was assigned to the acupressure group and the letter $C$ to the control group. Each patient selected an envelope, which was then opened by the investigator. The groups were thus determined depending on which letter of envelope they chose. The pregnant women not fitting the criteria were excluded from the study. The SP6 acupressure was applied 35 times during uterine contractions, 15 times at $2-3 \mathrm{~cm}$ of cervical dilation, and 10 times each at 5-6 cm and 8-9 cm of cervical dilation. Before application of acupressure, the first SP6 point was anatomically located. The standard procedure in locating the correct point is to measure it with one's own finger width (Figure 2). This measurement is dependent on the meridian theory in which the measurement is performed using the reference of one's own body. Here, the patient's own anatomical measurements provide the proportional reference (Figure 2). At the same time, the acupuncture point detector was used for each pregnant woman in order to detect the SP6 point correctly. Afterwards, a green light and a special sound are emitted (21). Acupressure was applied by placing thumbs on both legs at the same time from the beginning to the end of the contraction (Figure 2). The mean pressure applied was about 3 to $5 \mathrm{~kg}$, and this amount was ascertained by the researcher. The thumbs of both hands (using not the edges but the round parts of the thumbs) were placed on the 
SP6 points (Figure 2). At the end of the contraction, pressure was gradually reduced and acupressure was stopped during the resting phase. The women were placed in a supine position with legs straight. During the acupressure procedure, uterine contractions and fetal heart rate were monitored with an electro-fetal monitor. Apart from the acupressure practice, the women were encouraged to get out of bed, sit and/or walk around as a part of their routine care. The researcher followed up on the women in both the acupressure and the control group during labor, answered their questions, and participated in their treatment and care. Except for the acupressure practice given to the acupressure group, the researcher gave the participants of both groups equal care throughout the labor. No problems were seen in the women or fetuses during the acupressure application. Subjective pain was measured using the Visual Analogue Scale (VAS) with ratings from 0-10; a higher score indicated more pain. The VAS was administered to the women five times in both the experimental and control groups. The first VAS evaluation(VAS1) was done before the acupressure practice; the second VAS evaluation (VAS 2) took place from the beginning to the end of a contraction at which time SP6 acupressure was applied 15 times with cervical dilation at $2-3 \mathrm{~cm}$. The third VAS evaluation (VAS 3) was performed from the beginning to the end of a contraction when SP6 acupressure was applied 10 times with cervical dilation at $5-6 \mathrm{~cm}$; the fourth VAS evaluation (VAS 4) documented at the beginning to the end of a contraction in which SP6 acupressure was applied 10 times when cervical dilation was 8-9 cm; and the final VAS evaluation (VAS 5) was completed during the early postnatal period at the second hour after delivery, before the mothers were discharged from the hospital. In the control group, the first VAS evaluation (VAS1) was done before the study, the second (VAS2) was performed after 15 contractions (when cervical dilation was $2-3 \mathrm{~cm}$ ) in the latent phase, the third VAS evaluation (VAS 3 ) was done after 10 contractions (when cervical dilation was $5-6 \mathrm{~cm}$ ) in the active phase, the fourth VAS evaluation (VAS 4) was performed after 10 contractions (when cervical dilation was 8-9 cm.) in the transition phase, and the final VAS evaluation (VAS 5) was completed in the early postpartum period (at the second hour, the end of the early postnatal period). The duration of labor to delivery was measured in two

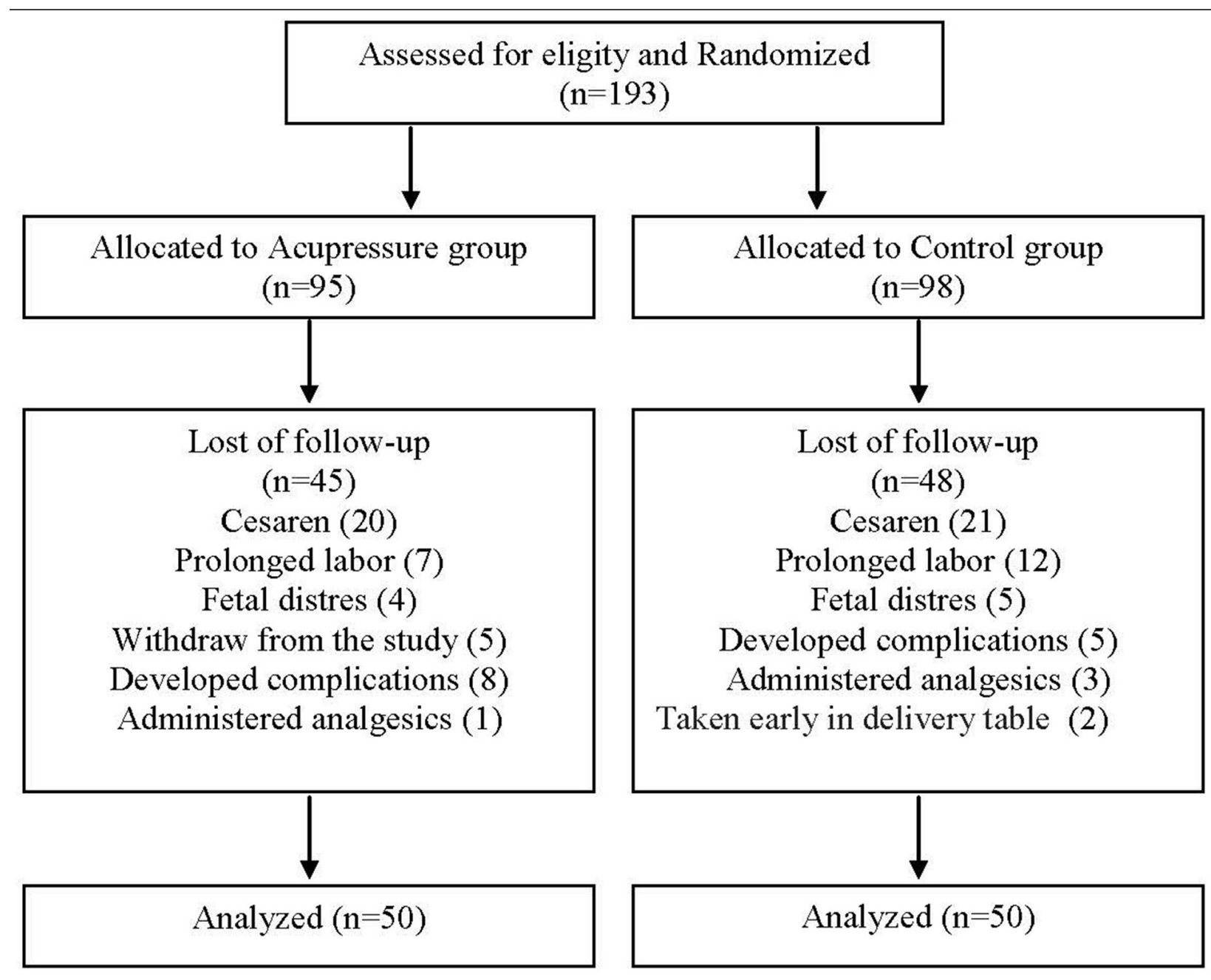

Figure 1. Flow Chart of Participants in Trial 

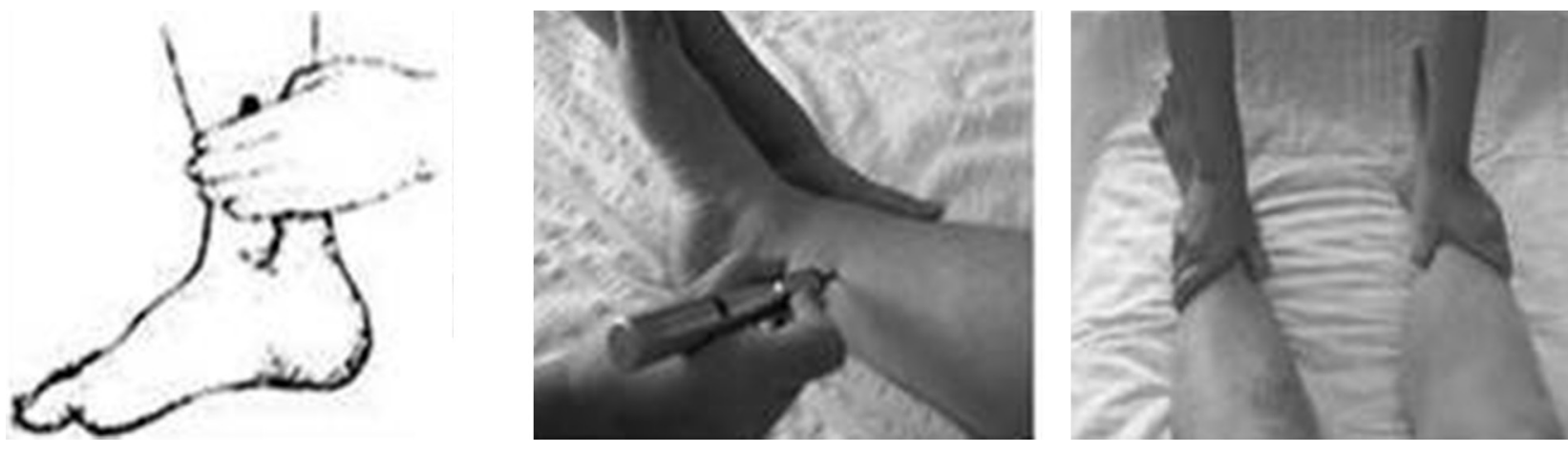

Figure 2. SP6 Acupoint and Acupressure Application

time periods from the participants' charts: from the 3-cm cervical dilation to full cervical dilation; and from full cervical dilation to delivery. The dilation of the uterine cervix was measured by midwives or doctors. The newborns' 1-minute and 5-minute APGAR scores and also mothers' pulses and breathing rates were recorded so that potential side effects of acupressure could be detected.

\subsection{Data Collection and Instruments}

\subsubsection{Questionnaire Form}

The form included questions related to the sociodemographic characteristics of the study participants and their medical and obstetric history. After reviewing the relevant literature $(1,2,6,8,9,19,22)$. The form was developed by the researcher to determine the backgrounds and sociodemographic characteristics of the women.

\subsection{Visual Analog Scale}

To define the perception of pain during labor, the Visual Analog Scale (VAS) was used. The VAS was the main assessment instrument of pain relief efficacy with a scale ranging from $0-10$, where 0 represented no pain and 10 the most pain. Although VAS is a subjective tool, it is widely applied and is a valid instrument for the assessment of pain $(6,9,14,18,19,23,24)$.

\subsection{Acumaster Acupuncture Pen}

Acumaster was designed both for searching out ear and body acupuncture points in the clinical practice of acupuncture and making ear diagnosis. The accuracy validation of the SP6 point finding for each subject was done using an electric acupoint detector, which emits green light when the correct site is touched. The detector used is Pyun-Jac Electro Acupointer (XFT-320; Shenzhen XFT Electronics Ltd., Guangdong, China) with the specifications of DC 9V. 1BAT and pulse wave, $12 \mathrm{~mA}, 1.8-12 \mathrm{~Hz}$. In addition, before the study began, the researcher was trained in the application of acupuncture by an acupuncture expert (21).

\subsection{Partograph}

The partograph is a tool developed by the WHO for application in order to direct labor action. The partograph records all observations made during a woman's labor and is a graphic on, which cervical dilatation is noted after a vaginal examination. By paying attention to the speed of cervical dilatation with the partograph, it is possible to detect abnormal slowing of the labor process and distinguish the cases that require special attention. The partograph helps detect abnormalities through recording all observations of labor activity on a chart and can prevent some problems by identifying these cases in the early stages $(1,22)$.

\subsection{Statistical Analysis}

The SPSS 17.0 package was used for statistical analysis. A one-sample Kolmogorov-Smirnov test was used to determine whether or not the data followed a normal distribution. Parametric tests were used for the analysis of the data that were normally distributed, whereas nonparametric tests were used for the analysis of the data that were not. The Chi-Square and Yates Chi-Square test were performed in order to determine whether the pregnant women in the acupressure and control groups showed a similar distribution in terms of socio-demographic and reproductive characteristics. Any possible differences between the acupressure and control groups in terms of pain levels and delivery time during labor were evaluated using the Mann-Whitney U test, and the mean, standard deviation (SD) minimum and maximum values were also used. A P Value of less than 0.05 was accepted as statistically significant.

\subsection{Ethical Consideration}

The study was approved by the institutional review 
board of the Marmara University Ethics Committee (reg.nr. B.30.2.MAR.0.01.02/AEK/504, 2009) and Trabzon Provincial Directorate of Health (reg.nr B-10-4ISM-4-61-00-01/251/17, 2009) Written informed consent was obtained from pregnant women, and the study protocol conformed to the ethical guidelines of the 1975 Declaration of Helsinki as reflected in a prior approval by the institution's human research committee.

\section{Results}

Table 1 shows the demographic characteristics of the 100 women who completed the study. There were no significant differences between the two groups in the variables of maternal age, education, gestational age, fear of labor, prenatal care received, and mean APGAR score in the 1st and 5th minutes $(\mathrm{P}>0.05)$. (Table 1) The women in the control group perceived pain more severely at nearly each level of labor (except VAS 1 and VAS 4) when compared with the women in the acupressure group (VAS 1: A: 3.00, C:3.00; VAS 2: 3.00, C:4.00; VAS 3: A: 7.00, C:8.00; VAS 4:10.0, C:10.0; VAS 5: A:2.0, C:3.0). The statistical analysis showed that the difference between the groups was highly significant in terms of perceived pain severity $(\mathrm{P}<0.001)$ (Table 2$)$. While first stage of labor was $225 \mathrm{~min}$ (3.75 hours) and the second stage was 15 min in pregnant women in the acupressure group, the I. stage lasted 320 minutes (5:33 hours), and the second stage lasted $20 \mathrm{~min}$ in the control group. The difference in duration of labor between the groups was found to be statistically significant in favor of the acupressure group $(P<0.001)$ (Table 3$)$.

Table 1. Characteristics of the Acupressure Group and Control Group $(n=100)$

\begin{tabular}{|c|c|c|c|c|}
\hline Variable & $\begin{array}{l}\text { Acupressure Group }(\mathbf{n}=\mathbf{5 0}) \text {. } \\
\text { No }(\%)\end{array}$ & $\begin{array}{c}\text { Control Group }(\mathbf{n}=\mathbf{5 0}) . \\
\text { No }(\%)\end{array}$ & Statistic $^{a}$ & PValue \\
\hline Age, y & & & 2.880 & 0.237 \\
\hline$\leq 19$ & $5(10.0)$ & $5(10.0)$ & & \\
\hline $20-24$ & $16(32.0)$ & $24(48.0)$ & & \\
\hline$\geq 25$ & $29(58.0)$ & $21(42.0)$ & & \\
\hline Educational Status & & & 4.026 & 0.134 \\
\hline $\begin{array}{l}\text { Primary school/ } \\
\text { Secondary School }\end{array}$ & $22(44.0)$ & $32(64.0)$ & & \\
\hline High School & $17(34.0)$ & $11(22.0)$ & & \\
\hline University Master & $11(22.0)$ & $7(14.0)$ & & \\
\hline Gestational Week & & & 4.456 & 0.035 \\
\hline 38-39 weeks & $22(44.0)$ & $12(24.0)$ & & \\
\hline 40-41 weeks & $28(56.0)$ & $38(76.0)$ & & \\
\hline Prenatal Care & & & 1.442 & 0.230 \\
\hline 4-8 times & $21(42.0)$ & $27(54.0)$ & & \\
\hline$\geq 9$ times & $29(58.0)$ & $23(46.0)$ & & \\
\hline Fear of Labor & & & 0.136 & $0.712^{b}$ \\
\hline $\begin{array}{l}\text { Fearful somewhat } \\
\text { fearful }\end{array}$ & $45(90.0)$ & $47(94.0)$ & & \\
\hline No fear & $5(10.0)$ & $3(6.0)$ & & \\
\hline \multicolumn{5}{|l|}{$\begin{array}{l}\text { APGAR score, mean } \pm \\
\text { SD }^{c}\end{array}$} \\
\hline $1 \mathrm{~min}$ & $7.46 \pm 0.54$ & $7.38 \pm 0.66$ & $\mathrm{U}=112500$ & 0.316 \\
\hline $5 \mathrm{~min}$ & $8.78 \pm 0.81$ & $8.75 \pm 0.82$ & $\mathrm{U}=119300$ & 0.670 \\
\hline
\end{tabular}

a For categorical data, $\mathrm{X}^{2}$ was performed, and for continuous variable, Mann-Whitney U Test was performed.

b Yates' corrected chi-square test was performed.

c Abbreviation: SD, standard deviation. 
Yesilcicek Calik K et al.

\begin{tabular}{|c|c|c|c|c|}
\hline Mean VAS Scores & Acupressure Group $(n=50)$ & Control Group $(\mathbf{n}=\mathbf{5 0})$ & Statistic & P Value \\
\hline VAS 1 before the practice & & & 1196.000 & 0.699 \\
\hline Median & 3.00 & 3.00 & & \\
\hline Mean Rank & 52.58 & 49.42 & & \\
\hline Min-Max & $1.00-5.00$ & $1.00-5.00$ & & \\
\hline $\begin{array}{l}\text { VAS } 2 \text { during the latent } \\
\text { phase }\end{array}$ & & & 660.000 & $<0.001$ \\
\hline Median & 3.0 & 4.0 & & \\
\hline Mean Rank & 38.70 & 62.30 & & \\
\hline Min-Max & $1.00-5.00$ & $3.00-9.00$ & & \\
\hline $\begin{array}{l}\text { VAS } 3 \text { during the active } \\
\text { phase }\end{array}$ & & & 681.500 & $<0.001$ \\
\hline Median & 7.0 & 8.0 & & \\
\hline Mean Rank & 39.13 & 61.87 & & \\
\hline Min-Max & $4.00-8.00$ & $5.00-10.00$ & & \\
\hline $\begin{array}{l}\text { VAS } 4 \text { during the } \\
\text { transition phase }\end{array}$ & & & 1200.000 & 0.463 \\
\hline Median & 10.0 & 10.0 & & \\
\hline Mean Rank & 49.50 & 51.50 & & \\
\hline Min-Max & $9.00-10.00$ & $9.00-10.00$ & & \\
\hline $\begin{array}{l}\text { VAS } 5 \text { at the } 2^{\text {nd }} \text { hour of } \\
\text { postpartum period }\end{array}$ & & & 509.000 & 0.000 \\
\hline Median & 2.0 & 3.0 & & \\
\hline Mean Rank & 35.68 & 65.32 & & \\
\hline Min-Max & $1.00-3.00$ & $1.00-5.00$ & & \\
\hline
\end{tabular}

Table 3. Comparison of Median Scores of Duration of Labor Between Acupressure Group and Control Group (Minutes)

\begin{tabular}{|c|c|c|c|c|}
\hline Labor Stages, min & Acupressure Group $(\mathbf{n}=\mathbf{5 0})$ & Control Group $(n=50)$ & Statistic $^{\mathrm{a}}$ & P Value \\
\hline $\begin{array}{l}\text { First stage (from } 3 \mathrm{~cm} \\
\text { dilation to } 10 \mathrm{~cm} \text { dilation }\end{array}$ & & & 586.000 & 0.000 \\
\hline Median & 225.00 & 320.00 & & \\
\hline Mean Rank & 37.22 & 63.78 & & \\
\hline Min-Max & $150.00-420.00$ & $240.00-460.00$ & & \\
\hline $\begin{array}{l}\text { Second stage (From } 10 \mathrm{~cm} \\
\text { dilation to delivery) }\end{array}$ & & & 812.000 & 0.002 \\
\hline Median & 15.00 & 20.00 & & \\
\hline Mean Rank & 41.74 & 59.26 & & \\
\hline Min-Max & $5.00-35.00$ & $5.00-45.00$ & & \\
\hline
\end{tabular}

a Mann-Whitney u test was performed.

\section{Discussion}

The purpose of this study was to evaluate the effects of acupressure on labor pain and duration of labor as perceived by pregnant women when acupressure was applied to the SP6 acupoint. The results indicate that the women in the control group perceived pain more severely at nearly each level of labor (except VAS 1 and VAS 4) when compared with the women in the acupressure group. Furthermore, the women in the control group were in labor 
more than one hour longer than those in the acupressure group. As already noted, the expressed pain scores in the acupressure group were found to be significantly lower than those in the control group. This demonstrates that acupressure application is an effective method in reducing the labor pain of pregnant women. In the evaluation of the initial pain (VAS 1) during the dilation of 2-3 cm (latent phase), the lack of difference between the two groups may be based on the fact that pregnant women were still in the early stages of labor, and it was administrated retrospectively before the application. The reason why there was no significant difference between the two groups in terms of the reduction of labor pain during the transition phase (VAS 4) may be explained with the change in the type of labor pain. This is due to the pressure on the surrounding tissue and organs as the baby's head settles into the pelvis during the transition phase and the reduction in the effect of acupressure during this period. In terms of the reduction of pain, acupressure might also be considered to be more effective for mild (latent phase) or moderate (active phase) pain. Similar results have been shown for studies in both Turkey and other countries, which also explored the effect of acupressure and other non-pharmacological methods on labor pain and the duration of labor $(6,8,9,24,25)$. Published studies of acupressure for treating labor pain have used different methodologies and either the L14 or SP6 acupressure points. The study of Kim et al. (10) concluded that acupressure performed on the SP6 and LI4 points was effective in controlling labor pain and reducing the duration of labor. In a study by Lee (14) in which acupressure was performed on the SP6 point for 30 minutes after cervical dilation was $3 \mathrm{~cm}$, it was found that pain in the experimental group decreased considerably compared to the control group. Another study's results determined that acupressure performed on the LI4 and BL67 points produced a difference between the groups in pain scores measured during the active phase of the first stage of labor. The length of first stage of labor in the experimental group was shorter than that of the control group (6). The randomized controlled study of Lee et al. (14) with 75 women reported that acupressure was applied to the SP6 point during each contraction, when cervical dilation was at least 2-3 cm and uterus contractions were regular for 30 minutes. Results showed a significant difference between the groups in the VAS scores following the acupressure intervention after 30 and 60 minutes. The same study also indicated that duration of labor in the SP6 group decreased significantly compared to the control group. Similarly, Kashanian and Shahali's (19) research, which investigated the effect of acupressure on the Sanyinjiao point on the duration of labor and labor pain, found that the severity of pain in the women in the study group was lower than those in the control group. They also reported that the duration of the active phase was shorter in the study group. Another study by Ozgoli et al. (25) found a significant difference in the pain scores of the experimental group as compared with the control group, when acupressure was performed on the LI4 point of the right hand during six uterus contractions with the cervix dilated at $4-5 \mathrm{~cm}$, 6-7 cm and 8-10 cm Similar findings were also reported in systematic screenings and studies related to acupuncture and acupressure practice used for labor pain management $(3,4,7,26,27)$. In contrast to our study, Mucuk et al. (28) and Ozturk et al. (23) reported no differences between pregnant women in the acupressure group and the control group. It is thus understood that the effects of acupressure on the duration of labor and labor pain differ in some studies, yet none of the studies mention any side effects of acupressure applied to specific sites. We believe that the different sample sizes and the use of different research methods may account for conflicting study results. When the APGAR scores of the newborn were analyzed to explore whether our non-pharmacological practices had any effect upon fetal health, no significant difference was noted between the first and fifth APGAR scores of the groups. Furthermore, other studies on the use of non-pharmacological methods do not reveal any significant differences in APGAR scores, and these results are consistent with those of our study $(8,19,23)$. Findings of this study indicate that the application of SP6 acupressure is an effective means in relieving pain during labor, and it also can shorten the duration of labor without causing harm to the mother and baby. Thus, acupressure can be readily implemented in clinical practice to improve the quality of care in labor and delivery. This present study has limitations in that only one acupuncture point was researched per group and the sample size was small. These points may prevent a generalization of our findings to different populations. In this study, potential confounding factors such as the parity, cervical dilation status, status of the amniotic membranes, and childbirth readiness were taken into account via randomization; hence these variables did not differ between groups, nor were there any differences in newborn weights. Various factors such as individual differences in pain limits and cultural, social, psychological, and mental factors could influence pain measurement. Furthermore, this study is important in terms of being the first in this field in the country of Turkey and it most definitely adds something new and important to the existing literature.

\section{Acknowledgements}

The authors are grateful to the women for their participation in this study. We would also like to thank the director of the college for her support and cooperation and Paula Maria Knauer for editorial support.

\section{References}

1. Komurcu N, Berkiten AE. Labor Pain and Management.Stanbul: Bedray Publishing Company; 2008.

2. Owen MD. Regional Analgesia in Labor In: Sahin S, Owen MD, eds Painless Labor and anesthesia in cesarean section.Stanbul, MA: Gunes Medicine Publishing;2006. 
3. Cook A, Wilcox G. Pressuring pain. Alternative therapies for labor pain management. AWHONN Lifelines. 1997;1(2):36-41.

4. Tournaire M, Theau-Yonneau A. Complementary and alternative approaches to pain relief during labor. Evid Based Complement Alternat Med. 2007;4(4):409-17.

5. Beal MW. Acupuncture and acupressure. Applications to women's reproductive health care. J Nurse Midwifery. 1999; 44(3) 217-30.

6. Chung UL, Hung LC, Kuo SC, Huang CL. Effects of LI4 and BL 67 acupressure on labor pain and uterine contractions in the first stage of labor. J Nurs Res. 2003;11(4):251-60.

7. Gentz BA. Alternative therapies for the management of pain in labor and delivery. Clin Obstet Gynecol. 2001;44(4):704-32.

8. Hamidzadeh A, Shahpourian F, Orak RJ, Montazeri AS, Khosravi A. Effects of LI4 acupressure on labor pain in the first stage of labor. J Midwifery Womens Health. 2012;57(2):133-8.

9. Hjelmstedt A, Shenoy ST, Stener-Victorin E, Lekander M, Bhat M, Balakumaran L, et al. Acupressure to reduce labor pain: a randomized controlled trial. Acta Obstet Gynecol Scand. 2010;89(11):1453-9.

10. Kim YR, Chag SB, Lee M K, Maeng WJ. Effects on labor pain and length of delivery time for primipara women treated by san-yinjian (SP-6) acupressure and hob-gog (LI-4) acupressure. Korean J Women Health Nurs. 2002;8(2):244-56.

11. Ma W, Bai W, Lin C, Zhou P, Xia L, Zhao C, et al. Effects of Sanyinjiao (SP6) with electroacupuncture on labour pain in women during labour. Complement Ther Med. 2011;19 Suppl 1:S13-8.

12. Hakverdioglu G, Turk G. Acupressure . Hacettepe Nurs School J. 2006;13.

13. Yesilcicek CK, Komurcu N. Acupressure . 2 edStanbul, MA: Nobel Medical Publishing; 2013.

14. Lee MK, Chang SB, Lee H. S., Kim HS. Effects of treatment with sanyin-jian (sp-6) acupressure for labor women on labor pain, length time for delivery and anxiety: A clinical trial pilot study. Korean J Women Health Nurs. 2002;8(4):559-69.
15. Betts D. Inducing labour with acupuncture-crucial considerations.J Chinese Med. 2009;90(1):20-5

16. Yıldırım, G. , Somek, A. A. , Kayır, H. . Establishment of the correlation between weight of the newborn and labor pain [Turkey]. Is tanbul Uni Florence Nightingale Health School J. 2006;15(57):99-107.

17. Dixon WJ, Massey FJ. Introduction to statistical analysis. 4 edUSA McGraw-Hill; 1983.

18. Lee MK, Chang SB, Kang DH. Effects of SP6 acupressure on labor pain and length of delivery time in women during labor. J Altern Complement Med. 2004;10(6):959-65.

19. Kashanian M, Shahali S. Effects of acupressure at the Sanyinjiao point (SP6) on the process of active phase of labor in nulliparas women. J Matern Fetal Neonatal Med. 2009:1-4

20. O'Brien RG, Muller KE. Applied analysis of variance in behavioral science marcel dekker.New York; 1983.

21. Osmaniye F, Çobançeșme, S. , Șahin Ap . diagnostics and ear acupuncture point detector. 2011.

22. Modares M, Mirmolaee ST, Mirmohammadalie M, et all. . The Effect of Education on the Use of Partogram to Control the Quality of Care Offered by Midwives. Res J Biol Sci. 2009;4(2):152-6.

23. Ozturk $\mathrm{CH}$, Saruhan A. Studying the effect of ice-massage applied to hands of pregnant women to reduce the perceived labor pains [Turkey]. J Nurs Res Develop. 2008;1(1):18-37.

24. Waters BL, Raisler J. Ice massage for the reduction of labor pain.J Midwifery Womens Health. 2003;48(5):317-21.

25. Ozgoli G, Sedigh S, Heshmat R, Alavi MH. Effect of right hand hegu acupressure on pain intensity of active phase of labor pain in primiparous women. Kowsar Medic J. 2010;14(4):229-34.

26. Haris PE. Acupressure: A review of the literature. Complementary Therapies in Medicine. 1997;3(5):156-61.

27. Huntley AL, Coon JT, Ernst E. Complementary and alternative medicine for labor pain: a systematic review. Am J Obstet Gynecol. 2004;191(1):36-44.

28. Mucuk S, Baser M. Effects of noninvasive electroacupuncture on labour pain and duration. J Clin Nurs. 2014;23(11-12):1603-10. 